\title{
Effects of progesterone, oestradiol benzoate and cloprostenol on luteal function in the heifer
}

\author{
R. K. Munro* and N. W. Moore \\ Department of Animal Husbandry, University of Sydney, Camden, New South Wales 2570, \\ Australia
}

\begin{abstract}
Summary. The effects of treatment with intravaginal progesterone (PRID) oestradiol benzoate and cloprostenol at various stages of the oestrous cycle were examined in 2 experiments. In Exp. 1, PRIDs were inserted for 14 days commencing on Day 3, 10 or 17 of the oestrous cycle and half the animals in each group received $5 \mathrm{mg}$ oestradiol benzoate at PRID insertion. Plasma samples were collected daily from the time of PRID insertion for 16 days, then every 4 days for a further 24 days. Samples were analysed for plasma progesterone concentration. In Exp. 2, heifers were treated on Day 10 as in Exp. 1, but half of each treatment group received $750 \mu \mathrm{g}$ cloprostenol at PRID insertion. In Exp. 1, treatment with PRID alone appeared to inhibit endogenous progesterone production when treatment began on Day 3, but not when treatment began on Days 10 or 17. Treatment with oestradiol benzoate at the time of PRID insertion depressed progesterone levels, from about 2-5 days after injection. When treatment began on Day 10, the fall in progesterone levels after oestradiol benzoate was preceded by a marked rise in levels. In Exp. 2, treatment with cloprostenol markedly reduced peripheral concentrations of progesterone and also removed the effect of oestradiol. We suggest that oestradiol benzoate had a luteolytic effect, depressing luteal progesterone production when given on Days 3,10 or 17 and that when given on Day 10 there was a transitory luteotrophic effect which preceded its luteolytic action.
\end{abstract}

\section{Introduction}

Administration of progesterone by means of a progesterone-releasing intravaginal device (PRID: Ceva Australia) can be effective in controlling the time of oestrus and ovulation in cyclic cows and can induce oestrus and ovulation in anoestrous cows (Roche, 1976; Bulman \& Lamming, 1978). Treatment periods of 14 days or longer give precise control of the time of oestrus but shorter periods of treatment control the time of oestrus less effectively because of residual luteal activity at the conclusion of the treatment (Roche \& Gosling, 1977; Roche, 1978). Progesterone treatments must approximate or exceed the length of the luteal phase of the oestrous cycle if treatment is to outlive the corpora lutea of all cows in randomly cycling herds. However, when exogenous progesterone is given within the first 3 days after oestrus the secretory life of the corpora lutea is substantially reduced (Ginther, 1971). When treatment periods of less than 14 days are used in randomly cycling herds, synchronization can only be achieved when luteolysins are included in treatment regimens. Oestrogens have been shown to possess both luteolytic and luteotrophic properties when given alone, or in association with progestagens (Wiltbank, 1966; Lemon, 1975) and oestradiol benzoate has been used with PRIDs to improve synchronization of oestrus (Roche, 1978). Prostaglandins

* Present address: CSIRO, Division of Tropical Animal Science, Tropical Cattle Research Centre, Box 5545, Rockhampton Mail Centre, Queensland 4702, Australia. 
have also been shown to be effective luteolysins (Cooper, 1974) and have been used to improve the synchronization of oestrus after short treatments with a PRID (Roche, 1976; Hansel \& Beal, 1979).

This study was designed to examine in some detail the effects of intravaginal treatment with progesterone and intramuscular injection of oestradiol benzoate and cloprostenol, at specific stages of the oestrous cycle, on the circulatory levels of progesterone.

\section{Materials and Methods}

Hereford and Hereford-cross heifers 18-22 months of age were used in 2 experiments. All were showing regular oestrous behaviour before experimentation and during the course of the experiment they were run under field conditions. To facilitate organization of the experiments the time of oestrus was synchronized by giving 2 intramuscular injections (i.m.) each of $500 \mu \mathrm{g}$ cloprostenol, (Estrumate: I.C.I.), 12 days apart (Exp. 1) or PRIDs inserted for 14 days (Exp. 2). All heifers were detected in oestrus within 3 days of the second cloprostenol injection or removal of PRIDs. The PRIDs used in the synchronization of oestrus and in the experiments contained $2.25 \mathrm{~g}$ progesterone.

Experiment 1. Nineteen heifers were allocated at random to treatment groups in a factorial experiment $(3 \times 2)$. PRIDs were inserted on Day 3, 10 or 17 (Day $0=$ day of oestrus) of the oestrous cycle following PG treatment and half of the heifers in each of the 3 groups received $5 \mathrm{mg}$ oestradiol benzoate i.m. at the time of PRID insertion. PRIDs were left in situ for 14 days.

Plasma samples for progesterone assay were collected by jugular venepuncture on Day 3 in all heifers and then daily until PRIDs were removed. After PRID removal animals were bled daily for 2 days and then once every 4 days until 26 days after PRID removal.

The heifers were observed for oestrous behaviour for $1 \mathrm{~h}$ beginning at $08: 00 \mathrm{~h}$ and at $17: 00 \mathrm{~h}$ for 4 days after PRID removal.

Experiment 2. A further 26 heifers were treated with a PRID starting on Day 10 of the oestrous cycle after synchronization. The heifers were allocated at random to 1 of 4 groups in an experiment of factorial design : the factors were (i) 0 versus $5 \mathrm{mg}$ oestradiol benzoate i.m. at PRID insertion, and (ii) 0 versus $750 \mu \mathrm{g}$ cloprostenol i.m. at PRID insertion. All PRIDs were left in situ for 14 days.

Plasma samples for progesterone assay were collected by jugular venepuncture immediately before the insertion of PRIDs on Day 10, and then daily until 3 days after the PRIDs were removed. Further samples were collected 12, 15, 19 and 27 days after PRID removal.

Observations for oestrus after PRID removal were as in Exp. 1.

Progesterone assay. About $10 \mathrm{ml}$ jugular vein blood from each animal were collected into a heparinized, evacuated glass tube at each bleeding time. The samples were kept at $4^{\circ} \mathrm{C}$ and centrifuged before plasma was aspirated. Plasma was stored at $-20^{\circ} \mathrm{C}$ until assayed.

Progesterone determinations were carried out using the competitive protein-binding assay described by Neill, Johansson, Datta \& Knobil (1967) and incorporating the modifications of Johansson (1969).

A light petroleum ether of boiling point $40-70^{\circ} \mathrm{C}$ (May and Baker, Australia) was used which did not extract steroids from plasma in amounts significantly different from those reported by Johansson (1969); $88 \% \pm 1 \%$ vs $86 \% \pm 3 \%$ (mean \pm s.e.m.) recovery of progesterone and 0.0 $0 \cdot 3 \%$ vs $0 \cdot 0-0 \cdot 3 \%$ (range) recovery of $\left[1,2-{ }^{3} \mathrm{H}\right]$ corticosterone respectively. The lowest concentration of progesterone distinguishable from zero was $0.2 \mathrm{ng} / \mathrm{ml}(P<0.001)$, while within-assay variation was $11.9 \%$ (coefficient of variation of duplicates of 24 unknown samples) and between-assay variation was $10 \cdot 1 \%$ (coefficient of variation of a sample in 20 assays).

Statistical procedures. Analyses of variance were used to examine the effects of treatment on plasma levels of progesterone. There was significant heterogeneity of variance (Bartlett's test) 
within these values. Transformation of the data by $\log _{10}(x+1)$ stabilized the variance within, but not between, groups treated at the same stage of the oestrous cycle.

The incidence of oestrus after PRID withdrawal was tested by using a $\chi^{2}$ test with Yates' correction for continuity.

\section{Results}

\section{Experiment 1}

Progesterone concentrations during treatment starting on Day 3. Progesterone values rose rapidly after PRID insertion (Text-fig. 1a) and declined during the period of PRID treatment (linear day of bleed effect, $P<0.001$ ). Concentrations in animals that received oestradiol declined more rapidly than in those that had not been given oestradiol (oestradiol $\times$ linear day of bleed interaction, $P<0.025)$.

Progesterone concentrations during treatment starting on Day 10. In heifers that received oestradiol, plasma levels of progesterone were initially higher and subsequently lower (oestradiol $\times$ linear and quadratic day of bleed interactions, $P<0.001$ ) than in those that had not been given oestradiol (Text-fig. $1 b$ ).

Progesterone concentrations during treatment starting on Day 17. After PRID insertion progesterone values in animals that received oestradiol failed to rise to those seen in heifers that had not received oestradiol (Text-fig. 1c) but at the conclusion of treatment concentrations were similar in both groups (oestradiol $\times$ linear day of bleed interaction, $P<0.001$ ).

The incidence of oestrus and progesterone concentrations after treatment. Of the 19 heifers, 13 showed standing oestrus after removal of PRIDs and all were first observed in oestrus $48 \mathrm{~h}$ after PRID removal. There was no effect of treatment on the incidence of oestrus.

After PRID removal the mean level of progesterone of most groups fell to around $1 \mathrm{ng} / \mathrm{ml}$ (Textfigs $1 \mathrm{a}, \mathrm{b} \& \mathrm{c})$. Concentrations began to rise between 6 and 10 days after PRID removal and fell from 18-22 days after removal. The peak values observed were lower in the groups treated on Day 3 than in the other groups (day of insertion $\times$ linear day of bleed interaction, $P<0.01$ ).

\section{Experiment 2}

Progesterone concentrations during PRID treatment. The initial rise (Text-fig. 2) in progesterone values in heifers that did not receive cloprostenol was markedly greater than in those that did $(P<0.001)$. In heifers receiving cloprostenol there was no effect of oestradiol benzoate on progesterone levels whereas in those that did not receive cloprostenol there was a major effect of oestradiol on the pattern of progesterone concentrations (oestradiol benzoate $\times$ linear and quadratic day of bleed interactions, $P<0.001$ ).

The incidence of oestrus and progesterone concentrations after treatment. Of the 26 heifers, 17 showed standing oestrus after removal of PRIDs but there was no effect of treatment on the incidence of oestrus. All but one of the 17 were first observed in oestrus on the 2 nd day after removal; the remaining heifer first showed oestrus on the 3rd day.

After PRID removal progesterone concentrations fell and remained low for several days (Textfig. 2). By 12 days after withdrawal values had risen and then fallen again 19-27 days after PRID withdrawal.

\section{Discussion}

The results of Exp. 1 showed the effects of exogenous oestrogen and progesterone on peripheral plasma progesterone concentrations when administered at various stages of the oestrous cycle. 

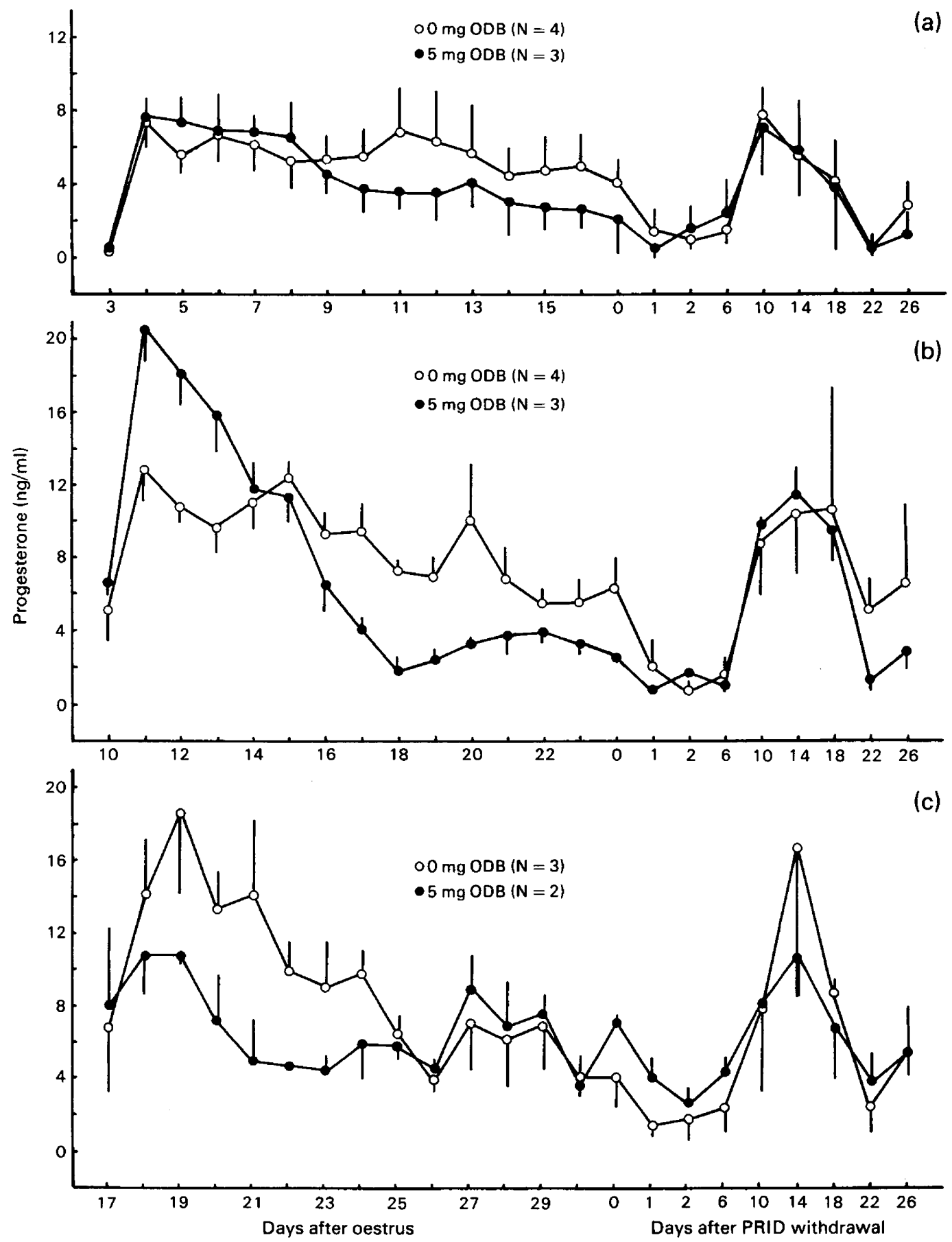

Text-fig. 1. Peripheral plasma levels (mean \pm s.e.m.) of progesterone in heifers in which PRIDs were inserted on (a) Day 3, (b) Day 10, and (c) Day 17 of the oestrous cycle (Exp. 1). 


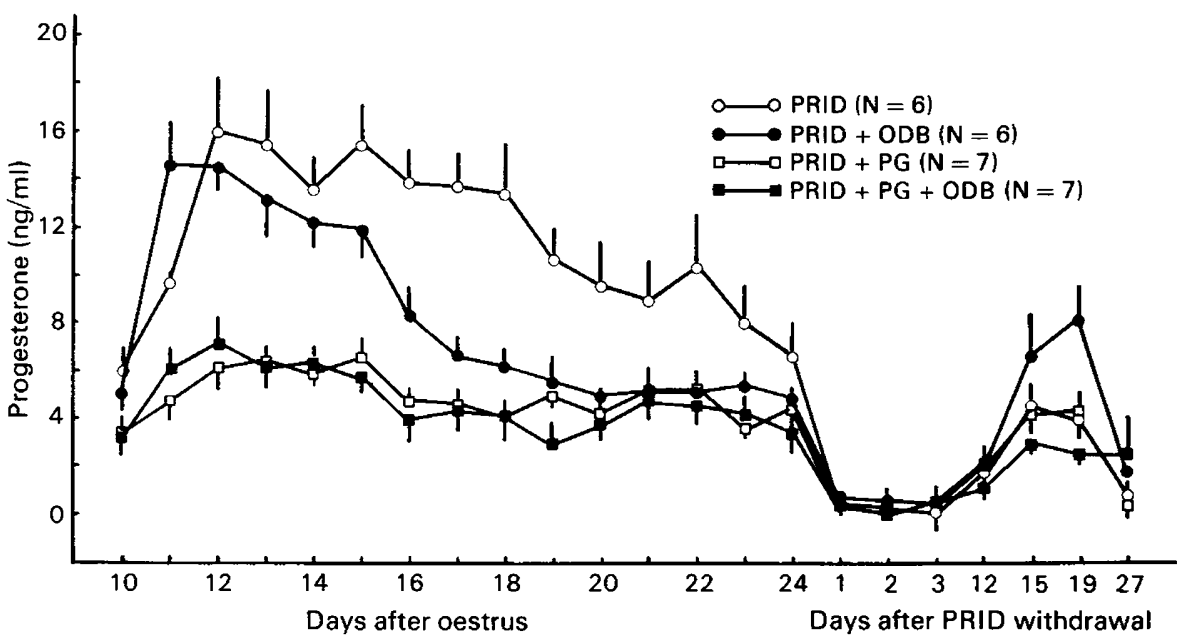

Text-fig. 2. Peripheral plasma levels (mean \pm s.e.m.) of progesterone in heifers in which PRIDs were inserted on Day 10 of the oestrous cycle (Exp. 2). PG, cloprostenol; ODB, oestradiol benzoate (see text).

After PRID insertion on Day 3 the initial rise in progesterone values did not continue and it appears that intravaginally administered progesterone, like injected progesterone (Loy, Zimbelman \& Casida, 1960; Woody, First \& Pope, 1967; Ginther, 1971), inhibits endogenous progesterone secretion if administered during the first few days after oestrus.

Overall, oestradiol benzoate depressed peripheral concentrations of progesterone but there were differences depending on the stage of the oestrous cycle at which it was administered. When given on Day 3 the depression in values was relatively small and did not become apparent until around 7 days after injection. When given on Day 10 the depression was marked and again became apparent about 7 days after injection but was preceded by a marked rise in concentrations not seen in heifers that did not receive oestradiol benzoate. In heifers given oestradiol on Day 17 the depression in progesterone concentrations occurred rapidly and was evident 2 days after injection. Oestradiol benzoate has been shown to be luteotrophic or luteolytic depending on the stage of the oestrous cycle at which it is administered (Wiltbank, Ingalls \& Rowden, 1961; Lemon, 1975; Gengenbach, 1976) and this could explain the changes in progesterone concentrations in Exp. 1. However, it is also possible that oestradiol benzoate altered the rate of absorption of exogenous progesterone through effects on vaginal secretions and vascularity, or altered the rates of transport and metabolism of progesterone.

Experiment 2 was designed to examine further the effects of oestradiol benzoate and in particular to determine whether the effects of oestradiol were mediated through the corpus luteum (CL) or through some other pathway. PG is an effective luteolysin (Cooper, 1974), and when administered to heifers at PRID insertion on Day 10, the resulting plasma progesterone levels were almost identical to those observed in heifers treated with PRID alone on Day 3 in Exp. 1 (see Textfigs $1 \& 2$ ). It would seem reasonable to assume that there was little progesterone of luteal origin secreted during treatment in either of these groups of animals and that the luteolytic action of PG was not impaired to any great extent by the concurrent administration of exogenous progesterone.

The animals that received a PRID or a PRID and oestradiol benzoate behaved similarly in Exps 1 and 2. The initial rise in progesterone concentrations in animals treated with a PRID and oestradiol was not as marked in Exp. 2 as in Exp. 1 although the nature and level of significance of the effects of oestradiol were the same in both experiments (oestradiol benzoate $\times$ linear and quadratic day of bleed interactions, $P<0.001$ ). The lower progesterone concentrations seen in 
Exp. 2 may be a reflection of the small number of animals used or the different techniques used to synchronize oestrus before treatment. It is difficult to visualize how the pretreatment regimens would have exerted an effect since all the heifers had shown oestrous behaviour and had normal luteal-phase levels of progesterone before treatment began. In addition, heifers treated with a PRID or with a regimen of 2 injections of PG have been shown to have similar pregnancy rates when inseminated within $24 \mathrm{~h}$ after the onset of oestrus following treatment (Smith et al., 1984).

The rise in progesterone concentrations seen in heifers that received oestradiol benzoate in Exp. 2 was not observed in the 2 groups which had received $P G$ and it would appear that a functional CL must be present if injection of oestradiol is to be followed by a rise in progesterone concentrations. Similarly, the large fall in progesterone values seen from Day 15-17 in the PRID + oestradiol group was greatly reduced by administration of PG and this effect would also appear to be largely dependent on the presence of a functional $\mathrm{CL}$. These findings suggest that oestradiol benzoate exerted both luteotrophic and luteolytic effects.

Oestrogens have been shown to cause the release of luteinizing hormone (LH) but not when luteal-phase concentrations of progesterone are present (Hobson \& Hansel, 1972; Short, Randel, Staigmiller \& Bellows, 1979), as was the case in these experiments. It would seem unlikely then that oestradiol benzoate exerted its luteotrophic effect on Day 10 by affecting $\mathrm{LH}$ release.

It is apparent that the large fall in progesterone concentrations seen 5-7 days after PRID + oestradiol treatment on Day 10 was due to luteolysis and the smaller falls 5-7 and 2-4 days after PRID + oestradiol treatment on Days 3 and 17, respectively, were probably also due to oestrogen-induced luteolysis. If this is so then it would indicate that the responsiveness to oestradiol benzoate of the luteolytic system becomes faster as the oestrous cycle progresses. It has been suggested that oestrogens are involved in natural luteolysis and in the luteal regression induced by exogenous PG (Hansel, 1975; Hixon et al., 1983). It would appear that injections of oestradiol benzoate have hastened the luteolytic processes, although in the cow the exact nature of these processes has yet to be defined.

In untreated cows the CL normally stops secreting progesterone by Day 20 (Henricks, Dickey \& Hill, 1971 ; Shemesh, Lindner \& Ayalon, 1971), but in heifers treated with a PRID alone on Day 10 progesterone concentrations as late as Day 20 to 24 exceeded the values observed in heifers treated with PG or oestradiol or both. It would seem valid to assume that progesterone secretion by the CL would have ceased by that time in animals that received $P G$ or oestradiol and the higher levels seen in animals treated with a PRID alone suggest that this treatment has allowed persistence of some luteal function past its normal duration in the oestrous cycle. It may be that progesterone, like oestradiol benzoate, has both luteolytic and luteotrophic actions depending on the stage of the oestrous cycle at administration.

We thank Ceva Australia for the PRIDs used in these studies and Mr Chris Stimson, Mr John Ellsmore and Ms Marie Blake for excellent technical assistance.

\section{References}

Bulman, C.D. \& Lamming, G.E. (1978) Milk progesterone levels in relation to conception, repeat breeding and factors influencing acyclicity in dairy cows. J. Reprod. Fert. 54, 447-458.

Cooper, M.J. (1974) Control of oestrous cycles of heifers with a synthetic prostaglandin analogue. Vet. Rec. 95, 200-203.

Gengenbach, D.R. (1976) The role of oestrogen in luteal regression in the cow and ewe. Diss. Abstr. Int. 36, 4324.

Ginther, O.J. (1971) Effect of progesterone on lengths of estrous cycle in cattle. Am. J. vet. Res. 31, 493-496.
Hansel, W. (1975) Luteal regression in domestic animals. Annls Biol. anim. Biochim. Biophys. 15, 147-160.

Hansel, W. \& Beal, W.E. (1979) Ovulation control in cattle. In Beltsville Symp. Agric. Res. Anim. Reprod. 3, 91-110.

Henricks, D.M., Dickey, J.F. \& Hill, J.R. (1971) Plasma estrogen and progesterone levets in cows prior to and during estrus. Endocrinology 89, 1350-1355.

Hixon, J.E., Pimentel, C.A., Weston, P.G., Chafetz, E.P., Shanks, R.D. \& Hansel, W. (1983) A luteolytic interaction between estradiol benzoate and prostaglandin $\mathrm{F}_{2 \alpha}$ in cattle. J. Anim. Sci. 56, 1190-1197. 
Hobson, W.C. \& Hansel, W. (1972) Plasma LH levels after ovariectomy, corpus luteum removal and estradiol administration in cattle. Endocrinology 91, 185190.

Johansson, E.D.B. (1969) Progesterone levels in peripheral plasma during the luteal phase of the normal human menstrual cycle measured by a rapid competitive protein binding technique. Acta endocr., Copenh. 61, 592-606.

Lemon, M. (1975) The effect of oestrogens alone or in association with progestagens on the formation and regression of the corpus luteum of the cyclic cow. Annls Biol. anim. Biochim. Biophys. 15, 243-253.

Loy, R.G., Zimbelman, R.G. \& Casida, L.E. (1960) Effects of injected ovarian hormones on the corpus luteum of the estrual cycle in cattle. J. Anim. Sci. 19, 175-182.

Neill, J.D., Johansson, E.D.B., Datta, J.K. \& Knobil, E. (1967) Relationship between the plasma levels of luteinizing hormone and progesterone during the normal menstrual cycle. J. clin. Endocr. Metab. 27, 1167-1173.

Roche, J.F. (1976) Synchronization of oestrus in cattle. World Review Animal Production 12, 79-88.

Roche, J.F. (1978) Control of estrus in cattle using progesterone coils. Anim. Reprod. Sci. 1, 145-154.

Roche, J.F. \& Gosling, J.P. (1977) Control of estrus and progesterone levels in heifers given intravaginal pro- gesterone coils and injections of progesterone and estrogen. J. Anim. Sci. 44, 1026-1029.

Shemesh, M., Lindner, H.R. \& Ayalon, N. (1971) Competitive protein-binding assay of progesterone in bovine jugular venous plasma during the oestrous cycle. J. Reprod. Fert. 26, 167-174.

Short, R.E., Randel, R.D., Staigmiller, R.B. \& Bellows, R.A. (1979) Factors affecting estrogen-induced LH release in the cow. Biol. Reprod. 21, 683-689.

Smith, R.D., Pomerantz, A.J., Beal, W. E., McCann, J.P., Pilbeam, T.E. \& Hansel, W. (1984) Insemination of Holstein heifers at a preset time after estrous cycle synchronization using progesterone and prostaglandin. J. Anim. Sci. 58, 792-800.

Wiltbank, J.N. (1966) Modification of ovarian activity in the bovine following injection of oestrogen and gonadotrophin. J. Reprod. Fert., Suppl. 1, 1-8.

Wiltbank, J.N., Ingalls, J.E. \& Rowden, W.W. (1961) Effects of various forms and levels of estrogens alone or in combination with gonadotrophins on the estrous cycle of beef heifers. J. Anim. Sci. 20, 341-346.

Woody, C.O., First, N.L. \& Pope, A.L. (1967) Effect of exogenous progesterone on estrous cycle lengths. $J$. Anim. Sci. 26, 139-141.

Received 31 May 1984 